This item was submitted to Loughborough's Research Repository by the author.

Items in Figshare are protected by copyright, with all rights reserved, unless otherwise indicated.

\title{
Bioinspired poly(vinylidene fluoride) membranes with directional release of therapeutic essential oils
}

\section{PLEASE CITE THE PUBLISHED VERSION}

https://doi.org/10.1021/acs.langmuir.8b01175

\section{PUBLISHER}

(c) American Chemical Society

\section{VERSION}

AM (Accepted Manuscript)

\section{PUBLISHER STATEMENT}

This work is made available according to the conditions of the Creative Commons Attribution-NonCommercialNoDerivatives 4.0 International (CC BY-NC-ND 4.0) licence. Full details of this licence are available at: https://creativecommons.org/licenses/by-nc-nd/4.0/

\section{LICENCE}

CC BY-NC-ND 4.0

\section{REPOSITORY RECORD}

Balzamo, G., Helen Willcock, Junaid Ali, Elizabeth Ratcliffe, and Elisa Mele. 2018. "Bioinspired Poly(vinylidene Fluoride) Membranes with Directional Release of Therapeutic Essential Oils". Loughborough University. https://hdl.handle.net/2134/35232. 
Bioinspired poly(vinylidene fluoride) membranes with directional release of therapeutic essential oils

G. Balzamo ${ }^{\dagger}$, H. Willcock ${ }^{\dagger}, J$. Ali ${ }^{\ddagger}$, E. Ratcliffe $e^{\ddagger}$ and E. Mele ${ }^{\dagger *}$

${ }^{\dagger}$ Department of Materials, Loughborough University, Epinal Way, Loughborough, LE11 3TU, UK.

${ }^{\ddagger}$ Department of Chemical Engineering, Loughborough University, Epinal Way, Loughborough, LE11 3TU, UK

*E-mail address: e.mele2@lboro.ac.uk

\begin{abstract}
Here, the morphology of Polypore fungi has inspired the fabrication of poly(vinylidene fluoride) (PVDF) membranes with dual porosity by non-solvent induced phase separation (NIPS). The fruiting body of such microorganisms is constituted of two distinct regions, finger- and spongelike structures, which have been successfully mimicked by controlling the coagulation bath temperature during the NIPS process. The use of water at $10{ }^{\circ} \mathrm{C}$ as coagulant resulted in membranes with the highest finger-like/sponge-like ratio (53\% of the total membrane thickness), whilst water at $90{ }^{\circ} \mathrm{C}$ allowed the formation of macrovoid-free membranes. The microchannels and the asymmetric porosity were used to enhance the oil sorption capacity of the PVDF membranes and to achieve directional release of therapeutic essential oils. These PVDF membranes with easily tuned asymmetric channel-like porosity and controlled pore size are ideal candidates for drug delivery applications.
\end{abstract}


Keywords: Phase separation; drug delivery devices; biomimetic structures; controlled porosity; plant extracts.

\section{Introduction}

The first time mankind employed fungi as source of food and therapeutic substances is dated back to primitive times. ${ }^{1-3}$ Since then these organisms have been thoroughly studied, especially for their bioactive molecules. ${ }^{4}{ }^{5}$ Many reports have revealed the beneficial properties of certain fungi for human health, including anti-tumour, antioxidant, anti-microbial, anti-inflammatory and immunostimulating activity. ${ }^{1-7}$ More recently, studies have focused also on analysing the morphology of fungi. ${ }^{8}$

The fruiting body of fungi basically consists of the spore-producing section (hymenophore) and the support sterile tissue (context). ${ }^{9}$ Within the group of Basidiomycetes fungi, the shape and morphology of hymenophore can vary greatly. ${ }^{10}$ In particular, the hymenophore of Polypores (Fig. 1a) possesses a well-structured tubelike morphology, ${ }^{11,12}$ formed of cylindrical and uniformly-distributed capillaries that are supported by the fibrous context, as shown by scanning electron microscopy (SEM) images in Fig. 1b and 1c. This highly optimised architecture is capable of releasing around 30 billion spores per day, ${ }^{13}$ which is ten times higher than the amount released by fungi with a lamellar structure (e.g. Agaricomycetes release around 2.7 billion per day). ${ }^{8}$

Taking inspiration from the unique dual porosity of polypore fungi, here the fabrication of poly(vinylidene fluoride) (PVDF) membranes that are characterised by the coexistence of one region with long ordered micro-channels and one region with spherical pores is demonstrated. The biomimetic membranes were obtained by nonsolvent induced phase separation (NIPS), ${ }^{14-17}$ using PVDF in dimethylformamide 
(DMF) as the casting solution (CS) and water as the coagulation bath (CB). By controlling the thermodynamics of the phase separation process, the size of the pores was adjusted from 1 to $3 \mu \mathrm{m}$ and the microchannel region was enlarged up to $53 \%$ of the total membrane thickness. Morphological and spectroscopic analyses were conducted to clarify the relationship between CB temperature and polymer precipitation rate. Although macrovoids have been already observed for PVDF membranes produced by NIPS, ${ }^{18-20}$ to the best of our knowledge a thorough study on the formation of a highly ordered array of microchannels distinctly separated from spherical pores has not been reported thus far. The presence of these well-defined and regular microchannels resulted in both an enhancement of the oil sorption capability of the membranes and the ability to directionally release antibacterial compounds. The bioinspired PVDF membranes with such dual porosity have the potential to be used as selective filtration devices and efficient drug delivery systems.

\section{Experimental section}

Materials. PVDF $\left(M_{\mathrm{w}}=275000 \mathrm{~g} / \mathrm{mol}\right.$ by Gel Permeation Chromatography, average $M_{\mathrm{n}}=107000 \mathrm{~g} / \mathrm{mol}$, density=1.78 $\mathrm{g} / \mathrm{mL}$ at $25^{\circ} \mathrm{C}$, melting temperature of $166-170{ }^{\circ} \mathrm{C}$ ) and DMF ( $\geq 99.0 \%$, density of $0.944 \mathrm{~g} / \mathrm{mL}$, boiling point of $153{ }^{\circ} \mathrm{C}$ ) were purchased from Sigma-Aldrich and used as received without further purification. Water with analytical grade purity was purchased from Fisher. Galwick wetting liquid (surface tension of $15.9 \mathrm{mN} / \mathrm{m}$ ) was supplied by Porous Materials Inc. (PMI). Highly refined mineral oil (Whitemor WOM 65) was purchased from Castrol Ltd, while tea tree oil (TTO) (100\% pure) was purchased from Freshskin Beauty Ltd. Lysogeny broth (LB) and agar were purchased from Sigma-Aldrich. Escherichia coli B strain was purchased from NCBE, University of Reading (United Kingdom). 
Preparation of the bioinspired PVDF membranes. Casting solutions at polymer concentration of $19 \mathrm{wt} \%$ were prepared by dissolving PVDF in DMF for 1 hour under stirring (150 rpm). The PVDF solutions were subsequently deposited onto a stainlesssteel metal support by a $500 \mu \mathrm{m}$ casting knife, and carefully immersed into a water bath. To prevent detachment of the membranes from the substrate and therefore ensure the formation of flat samples, loads were placed at the edges of the membranes when still in water. After 1 hour, the membranes were removed from the water bath and allowed to dry at room temperature under a fume-hood overnight. During the drying step, the wet membranes were kept attached to wet filter paper on both sides by means of pins, in order to reduce their shrinkage. The temperature of the coagulation bath $\left(T_{C B}\right)$ was varied from 10 to $90{ }^{\circ} \mathrm{C}$ in $10{ }^{\circ} \mathrm{C}$ increments; while the temperature of the casting solution $\left(T_{C S}\right)$ was $90^{\circ} \mathrm{C}$. All samples were stored in petri dishes at ambient conditions until characterisation.

The samples produced are hereafter referred to as $M T_{C S} / T_{C B}$ by considering the combinations of $T_{C S[C B]}$ used in the NIPS process.

Membrane characterisation. The morphology of surface and cross section of the membranes was analysed by SEM (Hitachi TM3030, Tokyo, Japan) using an acceleration voltage of $15 \mathrm{kV}$, and a field emission gun SEM (Zeiss LEO1530VP) for the high magnification images. Prior to transfer the samples into the SEM microscope chamber, a 10nm-thick gold/palladium (Au/Pd) film was deposited (Quorum Q150T ES sputter) as conductive covering layer. ImageJ (National Institutes of Health, USA) was used to calculate the finger-like/sponge-like (FL/SL) ratio.

The polymer precipitation rate, during the formation of the PVDF membranes, was measured by a Jenway 6705 UV-Vis Spectrophotometer. The light transmittance 
variation as a function of time was monitored through the nascent membrane submerged in water for 3 different values of $T_{C B}$.

Water contact angle (WCA) measurements were performed using a DataPhysics OCA 20 instrument with $1 \mu$ l droplet of de-ionized water. An average of 10 different zones per sample was analysed on both surfaces of the membranes.

The membrane porosity $(\varepsilon)$ was measured by gravimetric method by estimating the weight of liquid contained into the pores using the following formula: ${ }^{21}$

$\varepsilon=\frac{\left(w_{1}-w_{0}\right) / \rho_{\text {Galwick }}}{\left(w_{1}-w_{0}\right) / \rho_{\text {Galwick }}+w_{0} / \rho_{P V D F}} \times 100 \%$

where $w_{1}$ is the weight of the wet membrane; $w_{0}$ is the weight of the dry membrane; $\rho_{\text {Galwick }}$ and $\rho_{P V D F}$ are the density of Galwick and PVDF, respectively. Three measurements per each membrane type were performed using samples with an area of around $8 \mathrm{~cm}^{2}$. Galwick was used as wetting liquid due to its low surface tension (15.9 $\mathrm{mN} / \mathrm{m})$ and low vapour pressure $(1-20 \mathrm{~Pa}){ }^{22}$

The oil sorption capacity (g/g) was investigated by measuring the weight of the wet membranes after 1 hour of immersion into oil. Prior to do so, the samples were left dripping for 1 minute to remove the excess of oil from the surfaces. The following formula was used for the calculation: ${ }^{23}$

$Q=\frac{\left(M_{1}-M_{0}\right)}{M_{0}}$

where $M_{1}$ is the weight of the wet membrane after oil dripping and $M_{0}$ is the weight of the dry membrane before oil soaking.

The dynamics of oil absorption was analysed by light transmission tests. One side of the PVDF membrane (with sponge- or finger-like morphology) was exposed to white light, while one droplet of $1 \mu \mathrm{l}$ of tea tree oil was deposited on it. The sorption process was then recorded from the opposite side by a HD camera. The oil infiltration into the membrane porosity determined 
a colour change of the membrane from dark grey to light grey. The brightness of membrane regions wetted by the oil increased as the amount of oil absorbed increased. The frames recorded were processed by Photoshop software to determine the luminosity of those bright areas. The data obtained were normalised to the initial luminosity recorded.

Release profile of TTO from the membranes. The release of tea tree essential oil from M90/40 membrane was determined using a UV-visible spectrophotometer (Spectronic Helios Alpha Beta UV-Visible Spectrophotometer, Thermo Electronic Corporation). A preliminary experiment revealed an absorbance peak at $215 \mathrm{~nm}$ of TTO which was used to detect the oil release from the membrane. A droplet of $4 \mu \mathrm{L}$ of TTO was loaded onto the membrane from the sponge-like side. After the complete oil absorption, the membrane was let to float on DI water (water bath with a $10 \mathrm{~mL}$ volume). Aliquots were removed at multiple time points between 0 and 24 hours, and the oil concentration was evaluated through a calibration curve.

Antibacterial tests. The antimicrobial properties of PVDF membranes loaded with tea tree essential oil were tested against Escherichia coli, as a model microorganism. Discs of $10 \mathrm{~mm}$ were cut from PVDF membranes and sterilised in a solution of $70 \%$ ethanol in DI water. A volume of $4 \mu \mathrm{L}$ of TTO was loaded into each disc. Agar plates were previously prepared through inoculation of a single colony of E. coli from a fresh agar plate into $20 \mathrm{~mL}$ of LB broth. The bacteria were let to grow in a shake flask stirring at $225 \mathrm{rpm}$ for 16 hours. Then, a volume of $100 \mu \mathrm{L}$ of LB broth with $10^{6}$ bacteria cells $/ \mathrm{mL}$ was evenly spread out onto a freshly prepared agar plate using a L shaped spreader. The agar plates were dried out for 2 hours inside an incubator at $37^{\circ} \mathrm{C}$. The PVDF/TTO discs were place in contact with the surface of the solidified agar medium. After 24-hour incubation, photos of the zone of inhibition were taken and used to evaluate the 
antibacterial activity of PVDF/TTO samples against E. coli. PVDF discs without TTO were used as control samples.

Statistical analysis. For each set of results, independent trials were repeated at least three times. From raw data, mean and standard deviation (SD) were calculated. One-way analysis of variance (ANOVA) followed by Tukey's multiple comparison test with a confidence interval for mean of 95\% were used for analysing the results by IBM SPSS Statistics software. The values of the membrane porosity are presented as mean \pm SD of 3 independent trials. The values of the inhibition zone of the antibacterial tests represent means \pm SD of 8 separate experiments. A significance level of $p<0.05$ was considered significant.

\section{Results and discussion}

Effect of CB temperature on membrane morphology. The NIPS process used in this work to produce the biomimetic membranes is schematised in Fig. 2. The PVDF-DMF solution at $90{ }^{\circ} \mathrm{C}$ was first cast onto a flat metal substrate and then immersed in water to induce phase separation. The temperature of the water bath was varied from $90{ }^{\circ} \mathrm{C}$ to 10 ${ }^{\circ} \mathrm{C}$ and its effect on the morphology of the membranes was investigated. $T_{C B}$ variations are known to greatly affect the kinetics of the polymer precipitation process and they can be used to tune phase separation dynamics and consequently membrane structure. ${ }^{24}$, 25

As shown in Fig. 3a, when both the casting solution and the coagulation bath were kept at $90{ }^{\circ} \mathrm{C}(\mathrm{M} 90 / 90)$, the internal morphology of the membrane was dominated by closed spherical pores with an average diameter of $3 \mu \mathrm{m}$, forming a sponge-like structure, as reported in previous works. ${ }^{19}, 26,27$ Macrovoid initiation started also to appear underneath the membrane surface in direct contact with water. By progressively decreasing $T_{C B}$ (M90/80 and M90/70 in Fig. 3b and 3c, respectively), the width of the 
sponge-like region diminished and macrovoids became more evident on one side of the membrane. When $T_{C B}$ was $60{ }^{\circ} \mathrm{C}$ (M90/60 in Fig. 3d), the macrovoids were replaced by regular finger-like structures. Those features became more defined and narrow (average size in the range of 1-3 $\mu \mathrm{m}$ ) by further reducing the temperature of the water bath (Fig. 3e-3i).

As shown in Fig. 4, the width of the finger-like region increased by reducing $T_{C B}$. The FL/SL ratio was negligible for M90/90 membranes (FL/SL $\approx 2.5 \%$ ), which were predominantly characterised by a sponge-like morphology. Instead, the FL/SL ratio significantly increased by reducing the CB temperature, until overstepping $50 \%$ for $T_{C B} \leq 20{ }^{\circ} \mathrm{C}$. FL/SL ratios of $51.4 \%$ and $53.4 \%$ were measured for $\mathrm{M} 90 / 20$ and $\mathrm{M} 90 / 10$, respectively.

Previous studies have shown the formation of macrovoids and fingers due to the NIPS process. ${ }^{19,24,28-31}$ In the work of Zhang et al., PVDF membranes prepared using a casting temperature of $60{ }^{\circ} \mathrm{C}$ exhibited large and randomly distributed macrovoids, the crosssection of which was affected by the presence of water (non-solvent) in the casting solution. $^{28}$ Jung et al. observed that macrovoids were formed for low PVDF concentrations (15-20 wt.\%), whereas the addition of solvent into the coagulation bath determined the suppression of macrovoids. ${ }^{19}$ Our work highlights the possibility to accurately control the morphology and extension of regular finger-like structures by simply adjusting $T_{C B}$. The emergence and preservation of narrow fingers with a precise size distribution, and the existence of a net FL/SL separation within the PVDF membranes have not previously been demonstrated. The orderly array of finger-like structures produced mimic, even if at a smaller scale, the array of microchannels that is characteristic of Polypores. 
In order to further investigate how polymer precipitation during the NIPS process affects the membrane morphology, light transmittance tests were performed. ${ }^{32}{ }^{33}$ Fig. 5 shows the temporal evolution of the phase separation during immersion of the casting solution into the coagulant at various temperatures (inset of Fig. 5): $T_{C B}$ of $20^{\circ} \mathrm{C}$ (blue symbols), $50{ }^{\circ} \mathrm{C}$ (orange symbols) and $80^{\circ} \mathrm{C}$ (black symbols). Nearly $100 \%$ light transmittance was recorded at the beginning of the NIPS process for all three temperatures, due to the high transparency of the PVDF-DMF solution. When the phase separation started, the solidification of the solution resulted in an increased opacity of the cast material and, therefore, in a reduced light transmittance. The solidification of the PVDF-DMF solution began $15 \mathrm{~s}$ after immersion in water for $T_{C B}$ of $20^{\circ} \mathrm{C}$; whereas a shorter time (about 1-2 s) was measured for $T_{C B}$ of $50{ }^{\circ} \mathrm{C}$ and $80{ }^{\circ} \mathrm{C}$. The polymer precipitation process lasted about $100 \mathrm{~s}$, $55 \mathrm{~s}$ and $40 \mathrm{~s}$ for $T_{C B}$ of $20^{\circ} \mathrm{C}, 50^{\circ} \mathrm{C}$ and $80^{\circ} \mathrm{C}$, respectively. Therefore, the polymer precipitation rate increased by increasing the water temperature, in agreement with previous results. ${ }^{29}$

Polymer membranes produced by NIPS are characterised by the presence of a dense skin layer onto the surface in direct contact with the coagulation bath. ${ }^{34}$ The skin layer acts as a barrier to the solvent/non-solvent exchange and influences the morphology of the membrane. ${ }^{25,35-37}$ The mass transfer associated to the in-flow of non-solvent into the CS and to the out-flow of solvent into the CB is mainly responsible for thermodynamic instabilities within the homogeneous polymer solution and for phase separation. ${ }^{38}$ As a result, solvent-rich and polymer-rich regions are formed within the phase-separating system, eventually becoming the voids (solvent-rich zones) and the solid matrix (polymer-rich zones) of the final membrane. In our case, at high CB temperature (80 ${ }^{\circ} \mathrm{C}$ ), instantaneous liquid-liquid demixing happened, leading to initiation of macrovoids beneath the skin layer and formation of cellular morphology in the rest of the membrane 
(Fig. 3b). ${ }^{26,37,39}$ At low CB temperatures (20 and $50{ }^{\circ} \mathrm{C}$ ), instead, physical gelation of the polymer solution occurred first in the NIPS process. ${ }^{29}$ This gave enough time to the initiated macrovoids to grow during the phase separation process. ${ }^{40}$ The contraction force generated by the slow gelation of the surrounded polymer matrix compressed the macrovoids and determined the formation of finger-like pores (Fig. 3e and 3h). ${ }^{26,40,41}$ By reducing the coagulation temperature, the gelation process further impacted onto the membrane morphology.

Wetting properties of the membranes. Wettability and gravimetric tests were performed to investigate the effect of the diverse internal microstructures on surface properties, porosity and oil sorption of the bioinspired membranes produced.

As expected due to the chemical nature of PVDF, all membranes were oleophilic, with oil contact angles lower that $10^{\circ}$. Indeed, when mineral and tea tree oil droplets were placed in contact with the membrane surfaces, they promptly spread over the surface and were absorbed. Water contact angle (WCA) measurements showed that the PVDF membranes were hydrophobic with WCA higher than $85^{\circ}$ (Fig. 6a), as reported in previous studies. ${ }^{42}$ An additional distinction has been made between the wetting properties of finger-like or sponge-like side of the membranes. On the former surface, all membranes showed similar WCA values: $88^{\circ}, 90^{\circ}, 86^{\circ}$ and $91^{\circ}$ for $\mathrm{M90} / 20, \mathrm{M} 90 / 40$, M90/60 and M90/80, respectively. On the contrary, differences were recorded for the sponge-like side. While both M90/20 and M90/80 had similar WCA (around 90), M90/40 and M90/60 were more hydrophobic (103 ${ }^{\circ}$ and $98^{\circ}$ for M90/40 and M90/60, respectively). The increase in WCA can indicate a high surface roughness of the spongelike side of M90/40 and M90/60, which in turn is expected to enhance oil sorption. ${ }^{43-47}$ Therefore, the oil sorption capacity of the PVDF membranes produced at $T_{C B}$ of 40 and 
$60^{\circ} \mathrm{C}$ was potentially affected by a balance between internal morphology and superficial characteristics. Both M90/40 and M90/60 membranes possessed higher porosity than M90/20 and M90/80 membranes. As shown in Fig. 6b, the porosity of M90/40 and M90/60 was (69.4 \pm 0.9$) \%$ and $(68.5 \pm 0.7) \%$, respectively; whereas it was $(59.8 \pm 1.3) \%$ and (63.3 \pm 0.7$) \%$ for M90/20 and M90/80, respectively. The difference in porosity was statistically significant for M90/40 vs. M90/20 ( $p<0.00001)$ and M90/80 $(p<0.001)$, and for M90/60 vs. M90/20 ( $p<0.0001)$ and M90/80 ( $p<0.001)$. The histograms in Fig. 6c report a comparative investigation between oil sorption data and structural characteristics of the membranes. The lowest oil sorption features for both mineral oil and tea tree essential oil were achieved for membranes without regular finger-like structures (M90/80): $\approx 1.9 \mathrm{~g} / \mathrm{g}$ for mineral oil and $0.9 \mathrm{~g} / \mathrm{g}$ for tea tree oil. The presence of the microchannels, instead, determined an enhancement of oil sorption, with values of $2.2 \mathrm{~g} / \mathrm{g}$ (mineral oil) and $1.4 \mathrm{~g} / \mathrm{g}$ (tea tree oil) for M90/20, $3.0 \mathrm{~g} / \mathrm{g}$ (mineral oil) and $1.8 \mathrm{~g} / \mathrm{g}$ (tea tree oil) for M90/40 and $2.9 \mathrm{~g} / \mathrm{g}$ (mineral oil) and $1.8 \mathrm{~g} / \mathrm{g}$ (tea tree oil) for M90/60. In particular, M90/40 and M90/60 showed the highest performances for both oils. The values obtained can be better interpreted by considering the two different contributions to oil sorption, i.e. absorption and adsorption. The former is the quantity of oil being incorporated into the bulk of the membrane; the latter is referred to the amount of oil attached onto the membrane outer sides due to surface forces. ${ }^{48,49}$ These factors are mainly affected by the porosity and surface properties of the membranes. Light transmittance tests were conducted to investigate if the two sides of the PVDF membranes exhibited different oil sorption capabilities. All membranes analysed (M90/20, M90/40, M90/60 and M90/80) absorbed oil from the side with the spongelike morphology (Fig. 7a), with a fast oil infiltration in the first 20 s. Then, the process slowly progressed until stopping after 200 s, when the oil droplet was completely 
absorbed. Membrane M90/40 showed the highest light transmittance percentage, reaching the saturation plateau after $120 \mathrm{~s}$. The infiltration of oil into the membrane porosity determined a colour change of the membranes from dark grey to light grey (Fig. 7b). On the contrary, this change in colour was not observed when the oil droplet was placed in contact with the membrane side containing finger-like structures (Fig. 7c). The oil droplet spread out onto the surface, due to the low value of oil contact angle, but oil penetration through the membrane was not detected.

The morphology of the two surfaces of the asymmetric PVDF membranes affected the different oil sorption observed. In Fig. 8, SEM images of two selected membrane types are shown: M90/20 and M90/40. The surface of the sponge-like side (surface in contact with the substrate during the NIPS process, Fig. 8a and b) had a spherulitic morphology with agglomerates of globules that are typical of a precipitation process mostly dominated by crystallisation. ${ }^{50-52}$ As expected, the globular structures were much more evident at low temperature of the coagulation bath. The top and tilted view of the sponge-like side of the membranes show the presence of cracks and large pores that connect the surface to the internal porosity and facilitate the oil sorption. On the contrary, the surface of the finger-like side (the surface in direct contact with the coagulation bath, Fig. 8c and 8d) was dense with no visible macropores for both membranes. ${ }^{19,53}$ Consequently, the oil penetration from this side of the membrane was hindered.

Directional release of antibacterial essential oil. The asymmetric structures obtained by NIPS, together with the chemical and mechanical stability, and biocompatibility of PVDF ${ }^{16,}{ }^{29}$ make the membrane produced promising systems for controlling the release of bioactive compounds. ${ }^{54}$ PVDF and its copolymers are widely used in the biomedical field, particularly for their electroactive properties, thermal stability and good chemical 
resistance. ${ }^{55,56}$ Abzan et al. have recently developed microporous PVDF scaffolds by combining NIPS with thermal induced phase separation (TIPS) process. ${ }^{57} \mathrm{By}$ changing the temperature and composition of the coagulation bath, scaffolds with controlled porosity and mechanical properties were produced. They were proposed for nerve tissue regeneration, because of their ability to promote attachment and proliferation of PC12 cells (a rat neuronal cell line). In another study, porous films of PVDF and calcium phosphate (CaP) containing eucalyptus and tea tree essential oils have been studied as delivery devices. ${ }^{58}$ They showed antibacterial activity against E. coli and S. aureus and cytocompatibility for mouse mesenchymal cells (C3HIOT1) and mouse myoblasts (C2C12). Composite membranes of poly[(vinylidene fluoride)-co-trifluoroethylene] (P(VDF-TrFE) and NaY zeolite have been prepared by solvent casting for the controlled release of Ibuprofen (IBU).${ }^{59}$ The membranes were characterised by a porous structure due to spinodal decomposition and polymer crystallisation, and their release profile was influenced by the zeolite content. A fast release of IBU within the first 24 hours followed by a sustained release was obtained.

Here, tea tree essential oil was selected as model antibacterial agent, ${ }^{60,61}$ and its release from the two sides of the PVDF membranes was investigated. Membranes M90/40 were used due to the high oil sorption capacity. The release profile of the sponge-like and finger-like side of the membranes was analysed by detecting the water-soluble components of TTO (terpinen-4-ol, $\alpha$-terpineol, and 1,8-cineole) ${ }^{62}$ released in a water bath UV-visible spectroscopy (Figure S1). ${ }^{58,63}$ The sponge-like side exhibited a faster release (72 and 81\% after 1 and 2 hours, respectively) than the finger-like side (54 and 70\% after 1 and 2 hours, respectively). For antibacterial tests, all membranes were loaded with the essential oil from the side with open porosity (sponge-like morphology), as schematised in Fig. 9a. Then, the impregnated membranes were positioned onto agar 
plates containing E. coli: for half of the samples, the sponge-like side was in contact with the agar; for the other half, instead, the finger-like side was placed onto the gel. This testing procedure was used to demonstrate that the existence of one non-porous surface was advantageous for storing the essential oil inside the membrane and for achieving directional release.

Unloaded PVDF membranes were used as control and they were ineffective in stopping bacteria growth (Fig. 9b). On the contrary, the membranes loaded with tea tree oil prevented bacteria proliferation, as shown by the characteristic reduction of bacteria concentration around the discs (Fig. 9c). The oil released from the sponge-like side of the membrane produced a visible zone of inhibition (Fig. 9d) with an average diameter of (17.0 \pm 1.1$) \mathrm{mm}$ (the sample diameter was of $10 \mathrm{~mm}$ in diameter). A smaller halo with an average diameter of $(11.9 \pm 0.6) \mathrm{mm}$ was instead observed for the finger-like side, due to oil present onto the edges of the samples and to permeation of the most volatile components of the oil through the membrane. The difference in the halo diameter between the sponge-like and the finger-like side of the membranes was statistically significant with $p<0.00001$.

\section{Conclusions}

In this work, the fabrication of PVDF membranes with a morphology that recalled the fruiting body structure of polypore fungi was demonstrated. High $T_{C B}\left(90^{\circ} \mathrm{C}\right)$ produced macrovoid-free membranes, while the gradual decrease of the coagulation bath temperature led to the appearance and progressive lengthening of regular/narrow fingerlike structures. A prevalence of finger-like morphology along the membrane crosssection was achieved for $T_{C B} \leq 20^{\circ} \mathrm{C}$. 
Cross-section morphology and superficial properties were both influential over the oil sorption capacity of the biomimetic membranes produced. A convenient combination of accessible internal porosity and membrane/oil interaction was achieved at intermediate $T_{C B}\left(40\right.$ and $\left.60^{\circ} \mathrm{C}\right)$, resulting in the highest oil sorption performances. Interestingly, the two sides of the membranes showed different oil sorption, being the sponge-like morphology able to promote oil infiltration, whereas the finger-like structures stopped oil release. This characteristic was used to achieve directional delivery of antibacterial tea tree essential oil. When the sponge-like side was placed in contact with the agar plate containing $E$. coli, the membranes had a significant effect in inhibiting bacteria growth. The side with microchannels, instead, acted as a barrier for oil diffusion.

The asymmetric structure of the PVDF membranes produced possesses essential features for topical drug delivery applications, ${ }^{64}$ such as: the possibility to store a controlled amount of bioactive component within the membrane porosity; limited loss of the compound from the surface that is not in direct contact with the target tissue.

\section{Acknowledgements}

The authors acknowledge use of the facilities and the assistance of S. Fowler and K. Yendall in the Loughborough Materials Characterisation Centre. They also acknowledge D. Insley and M. Callender from the Materials Department Workshop for the production of the casting knife, S. Creedon from the Chemical Engineering Department and J. Bhuptani from the School of Architecture, Building and Civil Engineering for their support for the materials characterisation.

Supporting Information. Release profile of tea tree essential oil. 


\section{References}

(1) Kaya, M.; Akata, I.; Baran, T.; Menteş, A. Physicochemical Properties of Chitin and Chitosan Produced from Medicinal Fungus (Fomitopsis pinicola). Food Biophys. 2015, 10, 162-168.

(2) Cha, W. S.; Ding, J. L.; Choi, D. B. Comparative Evaluation of Antioxidant, Nitrite Scavenging, and Antitumor Effects of Antrodia Camphorata Extract. Biotechnol. Bioprocess Eng. 2009, 14, 232-237.

(3) Choi, D.; Maeng, J. M.; Ding, J. L.; Cha, W. S. Exopolysaccharide Production and Mycelial Growth in an Air-Lift Bioreactor Using Fomitopsis Pinicola. J. Microbiol. Biotechnol. 2007, 17, 1369-1378.

(4) Wasser, S. P. Medicinal Mushrooms as a Source of Antitumor and Immunomodulating Polysaccharides. Appl. Microbiol. Biotechnol. 2002, 60, 258-274.

(5) Lindequist, U.; Niedermeyer, T. H. J.; Jülich, W. D. The Pharmacological Potential of Mushrooms. Evid. Based Complement. Altern. Med. 2005, 2, 285-299.

(6) Grienke, U.; Zöll, M.; Peintner, U.; Rollinger, J. M. European Medicinal Polypores--A Modern View on Traditional Uses. J. Ethnopharmacol. 2014, 154, 564-583.

(7) Hao, L.; Sheng, Z.; Lu, J.; Tao, R.; Jia, S. Characterization and Antioxidant Activities of Extracellular and Intracellular Polysaccharides from Fomitopsis Pinicola. Carbohydr. Polym. 2016, 141, 54-59.

(8) Fischer, M. W.; Money, N. P. Why Mushrooms Form Gills: Efficiency of the Lamellate Morphology. Fungal Biol. 2010, 114, 57-63. 
(9) Prasher, I. B. Wood-rotting non-gilled Agaricomycetes of Himalayas, Springer Netherlands, Dordrecht, 2015.

(10) Miettinen, O.; Spirin, V.; Vlasák, J.; Rivoire, B.; Stenroos, S.; Hibbett, D. Polypores and Genus Concepts in Phanerochaetaceae (Polyporales, Basidiomycota). MycoKeys 2016, 17, $1-46$.

(11) Francis, C. M.; Schwarze, W. M. R.; Engels, J. Fungal Strategies of Wood Decay in Trees, Springer Science \& Business Media, 2013.

(12) Stolze-Rybczynski, J. L.; Cui, Y.; Stevens, M. H. H.; Davis, D. J.; Fischer, M. W. F.; Money, N. P. Adaptation of the Spore Discharge Mechanism in the Basidiomycota. PLoS One 2009, 4, e4163.

(13) Money, N. P. Mushroom, Oxford University Press, 2011.

(14) Wang, N.; Wang, T.; Hu, Y. Tailoring Membrane Surface Properties and Ultrafiltration Performances via the Self-Assembly of Polyethylene Glycol-block-Polysulfone-blockPolyethylene Glycol Block Copolymer upon Thermal and Solvent Annealing. ACS Appl. Mater. Interfaces 2017, 9, 31018- 31030.

(15) Woo, S. H.; Lee, J. S.; Lee, H. H.; Park, J.; Min B. R. Preparation Method of Crackfree PVDF Microfiltration Membrane with Enhanced Antifouling Characteristics. ACS Appl. Mater. Interfaces 2015, 7, 16466-16477.

(16) Hu, N.; Xiao, T.; Cai, X.; Ding, L.; Fu, Y.; Yang, X. Preparation and Characterization of Hydrophilically Modified PVDF Membranes by a Novel Nonsolvent Thermally Induced Phase Separation Method. Membranes 2016, 6, 47.

(17) Strathmann, H.; Kock, K. The Formation Mechanism of Phase Inversion Membranes. Desalination 1977, 21, 241-255.

(18) Liu, F.; Hashim, N. A.; Liu, Y.; Abed, M. R. M.; Li, K. Progress in the production and modification of PVDF membranes. J. Memb. Sci. 2011, 375, 1-27. 
(19) Jung, J. T.; Kim, J. F.; Wang, H. H.; di Nicolo, E.; Drioli, E.; Lee, Y. M. Understanding the Non-Solvent Induced Phase Separation (NIPS) Effect During the Fabrication of Microporous PVDF Membranes via Thermally Induced Phase Separation (TIPS). J. Membr. Sci. 2016, 514, 250-263.

(20) Hou, D.; Fan, H.; Jiang, Q.; Wang, J.; Zhang, X. Preparation and characterization of PVDF flat-sheet membranes for direct contact membrane distillation. Sep. Purif. Technol. 2014, 135, 211-222.

(21) Rajabzadeh, S.; Maruyama, T.; Ohmukai, Y.; Sotani, T.; Matsuyama, H. Effects of Additives on the Morphology and Properties of Poly(vinyledene Flouride) Blend Hollow Fiber Membrane Prepared by the Thermally Induced Phase Separation Method. Sep. Purif. Technol. 2009, 66, 76-83.

(22) Kolb, H. E.; Schmitt, R.; Dittler, A.; Kasper, G. On the accuracy of capillary flow porometry for fibrous filter media. Sep. Pur. Tech. 2018, 199, 198-205.

(23) Reshmi, C. R.; Suja, P. S.; Juraij, A.; Sujith, A. Fabrication of Superhydrophobic Polycaprolactone/Beeswax Electrospun Membranes for High-Efficiency Oil/Water Separation. RSC Adv. 2017, 7, 2092-2102.

(24) Amirilargani, M.; Saljoughi, E.; Mohammadi, T.; Moghbeli, M. R. Effects of Coagulation Bath Temperature and Polyvinylpyrrolidone Content on Flat Sheet Asymmetric Polyethersulfone Membranes. Polym. Eng. Sci. 2010, 50, 885-893.

(25) Shao, X.; Dong, D.; Parkinson, G.; Li, C.-Z. Microstructure Control of Oxygen Permeation Membranes with Templated Microchannels. J. Mater. Chem. A 2014, 2, 410-417.

(26) Cheng L. P. Effect of Temperature on the Formation of Microporous PVDF Membranes by Precipitation from 1-Octanol/DMF/PVDF and Water/DMF/PVDF Systems. Macromolecules 1999, 32, 6668-6674. 
(27) Wang, X.; Zhang, L.; Sun, D.; An, Q.; Chen, H. Formation mechanism and crystallization of poly(vinylidene fluoride) membrane via immersion precipitation method. Desalination 2009, 236, 170-178.

(28) Zhang, P.-Y.; Yang, H.; Xu, Z.-L. Preparation of polyvinylidene fluoride (PVDF) membranes via nonsolvent induced phase separation process using a Tween 80 and $\mathrm{H}_{2} \mathrm{O}$ mixture as an additive. Ind. Eng. Chem. Res. 2012, 51, 4388-4396.

(29) Wang, X.; Zhang, L.; Sun, D.; An, Q.; Chen, H. Effect of Coagulation Bath Temperature on Formation Mechanism of Poly(Vinylidene Fluoride) Membrane. J. Appl. Polym. Sci. 2008, 110, 1656-1663.

(30) Guo, Y.; Feng, X.; Chen, L.; Zhao, Y.; Bai, J. Influence of the Coagulation-Bath Temperature on the Phase-Separation Process of Poly(vinylidene fluoride)-graft-Poly(nisopropylacrylamide) Solutions and Membrane Structures. J. Appl. Polym. Sci. 2010, 116, 1005-1009.

(31) Jin, T.-T.; Zhao, Z.-P.; Chen, K.-C. Preparation of a Poly(Vinyl Chloride) Ultrafiltration Membrane through the Combination of Thermally Induced Phase Separation and Non-Solvent-Induced Phase Separation. J. Appl. Polym. Sci. 2016, 133, 42953.

(32) Young, T.-H.; Cheng, L.-P.; Lin, D.-J.; Fane, L.; Chuang W.-Y. Mechanisms of PVDF membrane formation by immersion-precipitation in soft (1-octanol) and harsh (water) nonsolvents. Polymer 1999, 40, 5315-5323.

(33) Li, Q.; Xu, Z.-L.; Yu, L.-Y. Effects of mixed solvents and PVDF types on performances of PVDF microporous membranes. J. Appl. Polym. Sci. 2010, 115, 22772287.

(34) Lu, W.; Yuan, Z.; Zhao, Y.; Zhang, H.; Zhang, H.; Li, X. Porous membranes in secondary battery technologies. Chem. Soc. Rev. 2017, 46, 2199-2236. 
(35) Young, T. H.; Chen, L. W. Pore Formation Mechanism of Membranes from Phase Inversion Process. Desalination 1995, 103, 233-247.

(36) Bottino, A.; Camera-Roda, G.; Capannelli, G.; Munari, S. The formation of microporous polyvinylidene difluoride membranes by phase separation. J. Membr. Sci. 1991, 57, 1-20.

(37) Yeow, M. L.; Liu, Y. T.; Li, K. Morphological Study of Poly(Vinylidene Fluoride) Asymmetric Membranes: Effects of the Solvent, Additive, and Dope Temperature. J. Appl. Polym. Sci. 2004, 92, 1782-1789.

(38) Mulder, M. Encyclopedia of Separation Science, Elsevier, 2000, pp. 3331-3346.

(39) Guillen, G. R.; Pan, Y.; Li, M.; Hoek, E. M. V. Preparation and Characterization of Membranes Formed by Nonsolvent Induced Phase Separation: A Review. Ind. Eng. Chem. Res. 2011, 50, 3798-3817.

(40) Yu, L.; Yang, F.; Xiang, M. Phase separation in a PSf/DMF/water system: a proposed mechanism for macrovoid formation. RSC Adv. 2014, 4, 42391-42402.

(41) Wang, B.; Lai, Z. Finger-like voids induced by viscous fingering during phase inversion of alumina/PES/NMP suspensions. J. Memb. Sci. 2012, 405-406, 275-283.

(42) Zheng, Z.; Gu, Z.; Huo, R.; Ye, Y. Superhydrophobicity of Polyvinylidene Fluoride Membrane Fabricated by Chemical Vapor Deposition from Solution. Appl. Surf. Sci. 2009, 255, 7263-7267.

(43) Abdullah, M. A.; Rahmah, A. U.; Man, Z. Physicochemical and Sorption Characteristics of Malaysian Ceiba Pentandra (1.) Gaertn. as a natural Oil Sorbent. $J$. Hazard Mater. 2010, 177, 683-691.

(44) Zhong, Z.; Xing W.; Zhang, B. Fabrication of Ceramic Membranes with Controllable Surface Roughness and Their Applications in Oil/Water Separation. Ceram. Int. 2013, 39, 4355-4361. 
(45) Gore, P. M.; Dhanshetty, M.; Balasubramanian, K. Bionic Creation of NanoEngineered Janus Fabric for Selective Oil/Organic Solvent Absorption. RSC Adv. 2016, $6,111250-111260$.

(46) Tuvshindorj, U.; Yildirim, A.; Ozturk, F. E.; Bayindir, M. Robust Cassie State of Wetting in Transparent Superhydrophobic Coatings. ACS Appl. Mater. Interfaces 2014, 6, 9680-9688.

(47) Bell, M. S.; Shahraz, A.; Fichthorn, K. A.; Borhan, A. Effects of Hierarchical Surface Roughness on Droplet Contact Angle. Langmuir 2015, 31, 6752-6762.

(48) Calvert, J. G. Glossary of atmospheric chemistry terms. Pure Appl. Chem. 1990, 62, 2167-2219.

(49) Vert, M.; Doi, Y.; Hellwich, K.-H.; Hess, M.; Hodge, P.; Kubisa, P.; Rinaudo, M.; Schué, F. Terminology for Biorelated Polymers and Applications. Pure Appl. Chem. 2012, 84, 377-410.

(50) Chang, H. H.; Chang, L. K.; Yang, C. D.; Lin, D. J.; Cheng, L. P. Effect of solvent on the dipole rotation of poly(vinylidene fluoride) during porous membrane formation by precipitation in alcohol baths. Polym. 2017, 115, 164-175.

(51) Drobek, M.; Figoli, A.; Santoro, S.; Navascués, N.; Motuzas, J.; Simone, S.; Algieri, C.; Gaeta, N.; Querze, L.; Trotta, A.; Barbieri, G.; Mallada, R.; Julbe, A.; Drioli, E. PVDF-MFI mixed matrix membranes as VOCs adsorbers. Microporous Mesoporous Mater. 2015, 207, 126-133.

(52) Peng, M.; Li, H.; Wu, L.; Zheng, Q.; Chen, Y.; Gu, W. Porous poly(vinylidene fluoride) membrane with highly hydrophobic surface. J. Appl. Polym. Sci. 2005, 98, 1358-1363.

(53) Xiao, T.; Wang, P.; Yang, X.; Cai, X.; Lu, J. Fabrication and characterization of novel asymmetric polyvinylidene fluoride (PVDF) membranes by the nonsolvent 
thermally induced phase separation (NTIPS) method for membrane distillation applications. J. Membr. Sci. 2015, 489, 160-174.

(54) Jeon, G.; Yang, S. Y.; Kim, J. K. Functional nanoporous membranes for drug delivery. J. Mater. Chem. 2012, 22, 14814.

(55) Martins, P.; Lopes, A.C.; Lanceros-Mendez S. Electroactive phases of poly(vinylidene fluoride): Determination, processing and applications. Progr. Polym. Sci. 2014, 39, 683-706.

(56) Marino, A.; Genchi, G. G.; Sinibaldi, E.; Ciofani, G. Piezoelectric effects of materials on bio-interfaces. ACS Appl. Mater. Interfaces 2017, 9, 17663-17680.

(57) Abzan, N.; Kharazihs, M.; Labbaf, S.; Saeidi, N. Modulation of the mechanical, physical and chemical properties of polyvinylidene fluoride scaffold via non-solvent induced phase separation process for nerve tissue engineering applications. Eu. Polym. J. 2018, 104, 115-127.

(58) Bagchi, B.; Banerjee, S.; Kool, A.; Thakur, P.; Bhandary, S.; Hoque, N. A., Das S. Synthesis of eucalyptus/tea tree oil absorbed biphasic calcium phosphate-PVDF polymer nanocomposite films: a surface active antimicrobial system for biomedical application. Phys. Chem. Chem. Phys. 2016, 18, 16775-16785.

(59) Salazar, H.; Lima, A. C.; Lopes, A. C.; Botelho, G.; Lanceros-Mendez, S. Poly(vinylidene fluoride-trifluoroethylene)/NAY zeolite hybrid membranes as a drug release platform applied to ibuprofen release. Colloids Surf. A: Physicochem. Eng. Aspects 2015, 469, 93-99.

(60) Zhang, W.; Ronca, S.; Mele, E. Electrospun Nanofibres Containing Antimicrobial Plant Extracts. Nanomaterials 2017, 7, 42. 
(61) Zhang, W.; Huang, C.; Kusmartseva, O.; Thomas, N. L.; Mele, E. Electrospinning of polylactic acid fibres containing tea tree and manuka oil. React. Funct. Polym. 2017, 117, 106-111.

(62) Carson, C. F.; Hammer, K. A.; Riley, T. V. Melaleuca alternifolia (Tea Tree) oil: a review of antimicrobial and other medicinal properties. Clin. Microbiol. Rev. 2006, 19, 50-62.

(63) Sotelo-Boyasa, M.; Correa-Pacheco, Z.; Bautista-Banosa, S.; Gomez y Gomez, Y. Release study and inhibitory activity of thyme essential oil-loaded chitosan nanoparticles and nanocapsules against foodborne bacteria. Int. J. Biolog. Macromol. 2017, 103, 409-414.

(64) Morgado, P. I.; Aguiar-Ricardo, A.; Correia, I. J. Asymmetric membranes as ideal wound dressings: An overview on production methods, structure, properties and performance relationship. J. Memb. Sci. 2015, 490, 139-151.

\section{Figures}




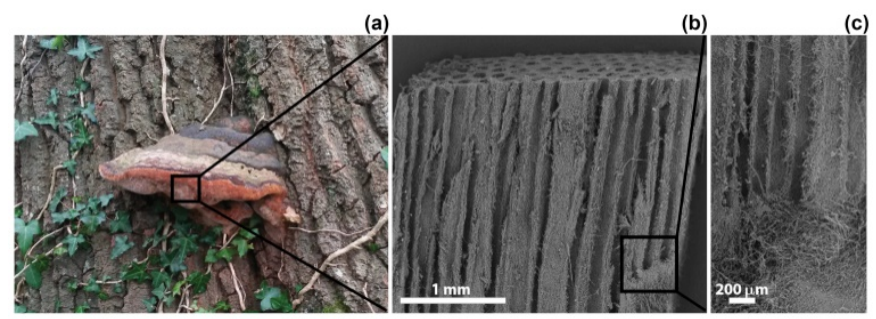

Figure 1. (a) Macro photograph of Fomitopsis pinicola (Polypore, Basidiomycete); SEM images of (b) the channel-like porosity of the hymenophore and (c) the interface between channel- and sponge-like structures. 


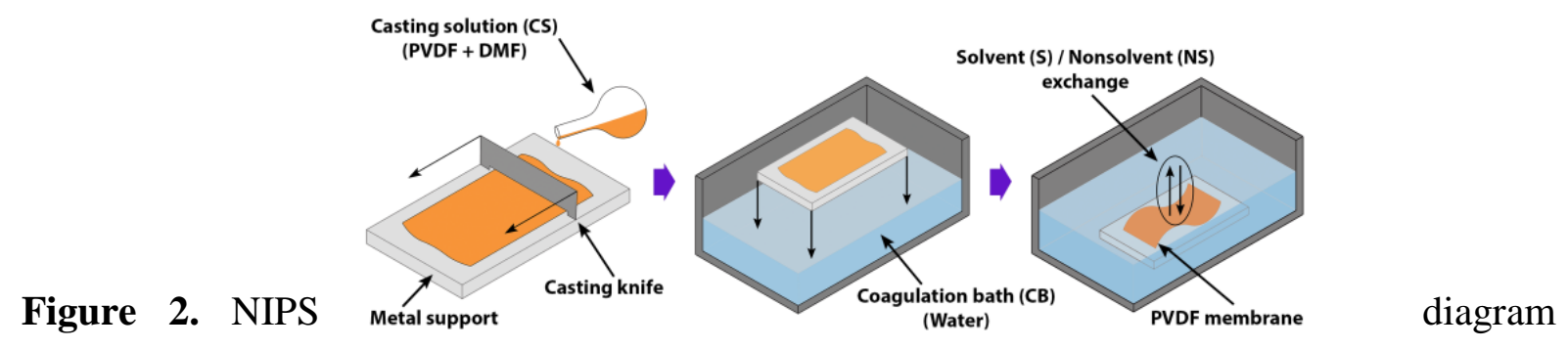

illustrating the main steps of the immersion precipitation methodology. 


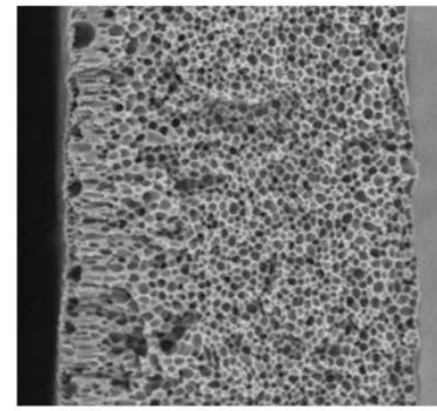

$50 \mu \mathrm{m}$

M90/90

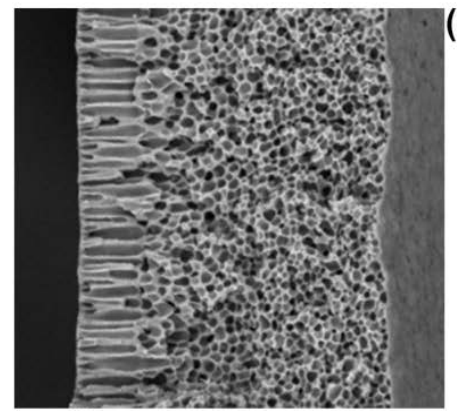

$50 \mu \mathrm{m}$

M90/60

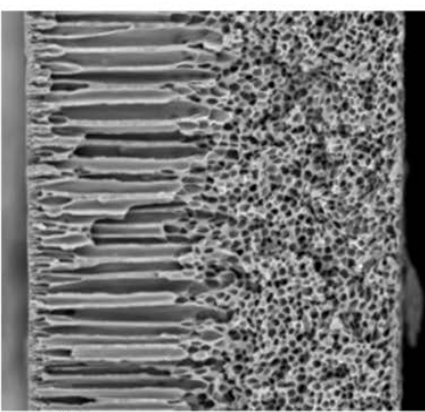

$50 \mu \mathrm{m}$

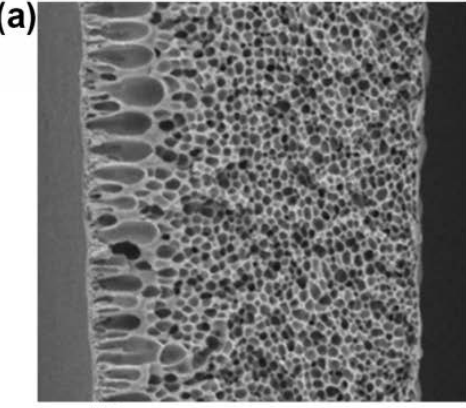

$50 \mu \mathrm{m}$

M90/80

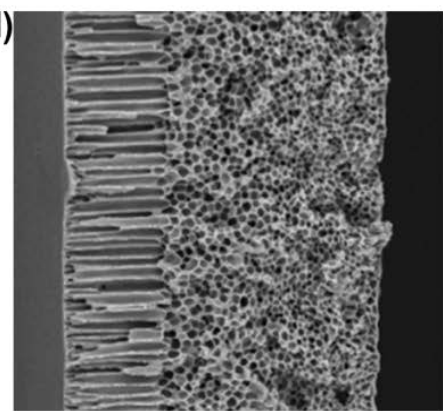

$50 \mu \mathrm{m}$

M90/50

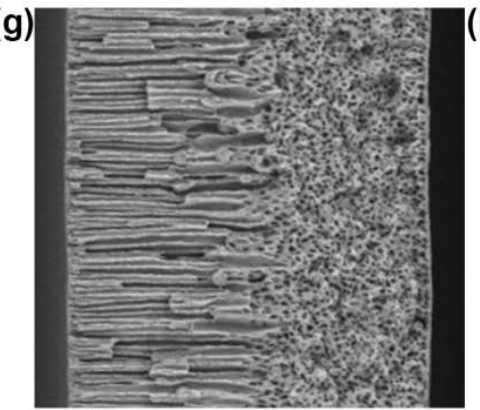

$50 \mu \mathrm{m}$ M90/30

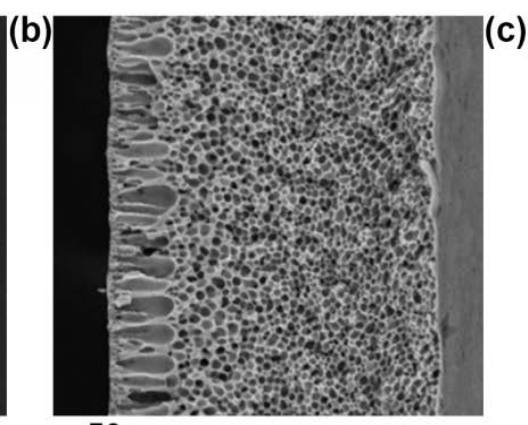

$50 \mu \mathrm{m}$

M90/70

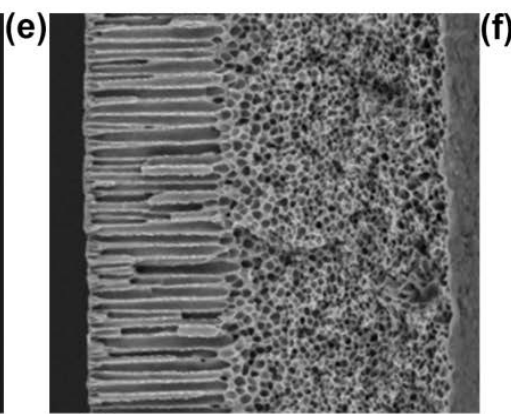

$50 \mu \mathrm{m}$

M90/40

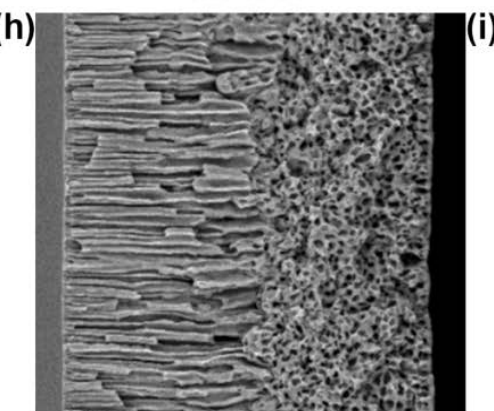

$50 \mu \mathrm{m}$ M90/10

Figure 3. SEM images of membrane cross-section evolution in relation to the coagulation bath temperature: (a) $90^{\circ} \mathrm{C}$, (b) $80^{\circ} \mathrm{C}$, (c) $70^{\circ} \mathrm{C}$, (d) $60^{\circ} \mathrm{C}$, (e) $50^{\circ} \mathrm{C}$, (f) $40^{\circ} \mathrm{C}$, (g) $30^{\circ} \mathrm{C}$, (h) $20^{\circ} \mathrm{C}$ and (i) $10^{\circ} \mathrm{C}$. 


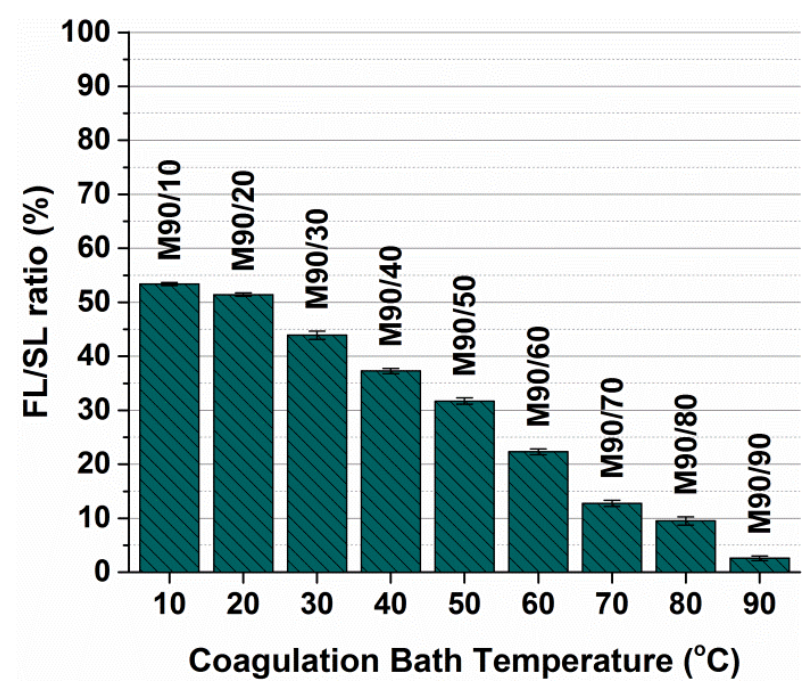

Figure 4. Effect of $T_{C B}$ on the finger-like/sponge-like ratio. 


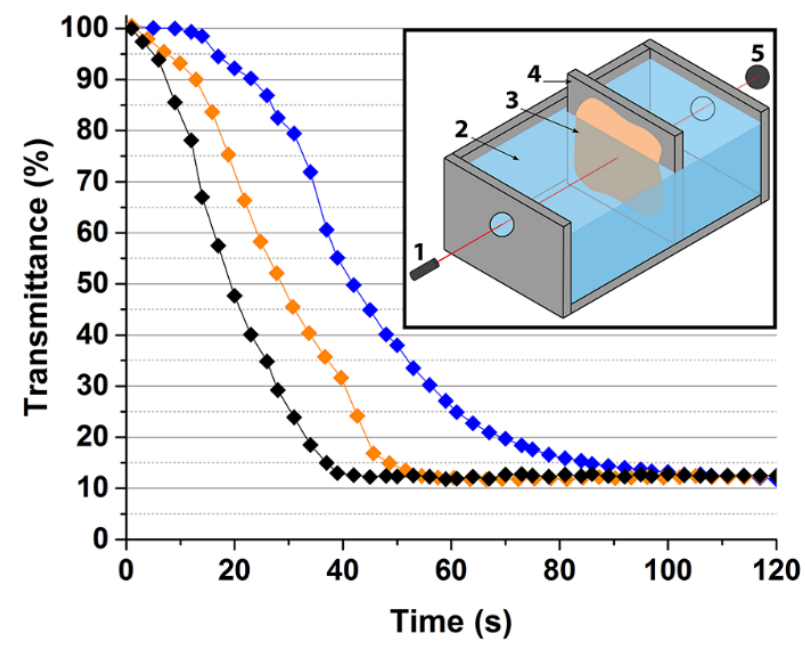

Figure 5. Light transmittance test for membranes produced at $T_{C B}$ of $20^{\circ} \mathrm{C}(\diamond), 50^{\circ} \mathrm{C}(\diamond)$ and $80^{\circ} \mathrm{C}(\diamond)$. The line between symbols is only a guide to the eye. Inset: Schematic illustration of the experimental setup used for the light transmittance tests. 1: incident light (wavelength $600 \mathrm{~nm})$, 2: coagulation bath, 3: casting solution, 4: support, 5: photodetector. 
(a)
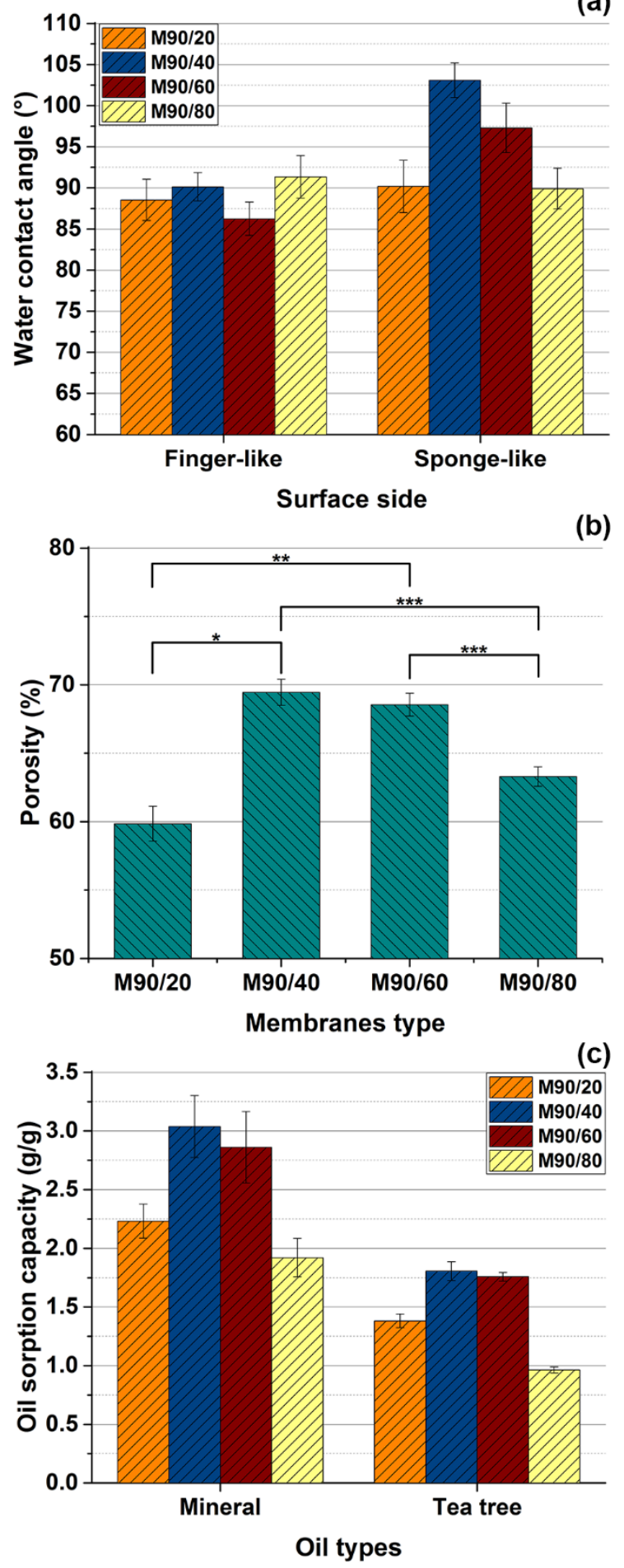

Figure 6. (a) WCA measurements for the finger-like and sponge-like surface of different membrane types (M90/20, M90/40, M90/60, M90/80). (b) Porosity of membranes M90/20, M90/40, M90/60 and M90/80. * $p<0.00001, * * p<0.0001, * * * p<0.001$. (c) Oil sorption capacity for mineral oil and tea tree oil. 
(a)

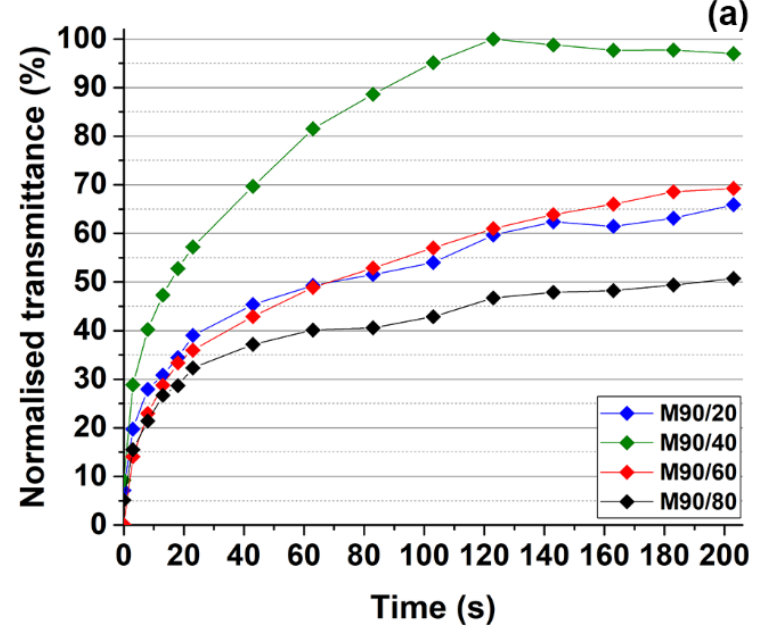

(b)

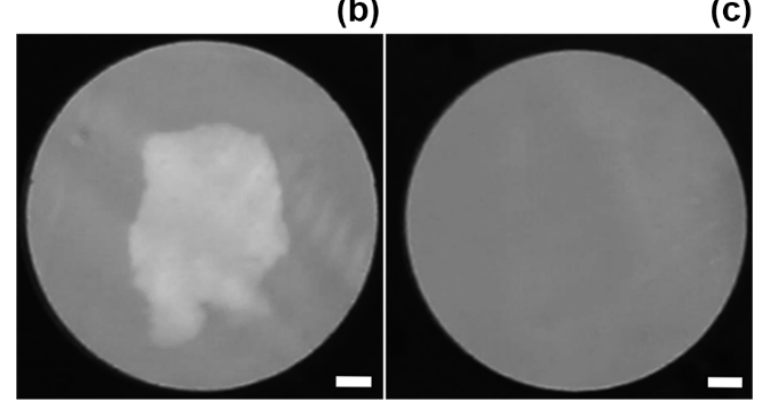

Figure 7. Normalised light transmittance vs. time for membranes M90/20, M90/40, M90/60, M90/80, using TTO as a test liquid. The TTO droplet was placed onto the membrane side with sponge-like morphology and the light transmittance was recorded from the side with fingerlike structures, and viceversa. Frames captured at 200 s for membrane M90/40, showing (b) regions with different colour when the oil was absorbed from the sponge-like side, and (c) no colour change when the oil was in contact with the finger-like side. Scale bar $=1 \mathrm{~mm}$. 
Sponge-like side - M90/20

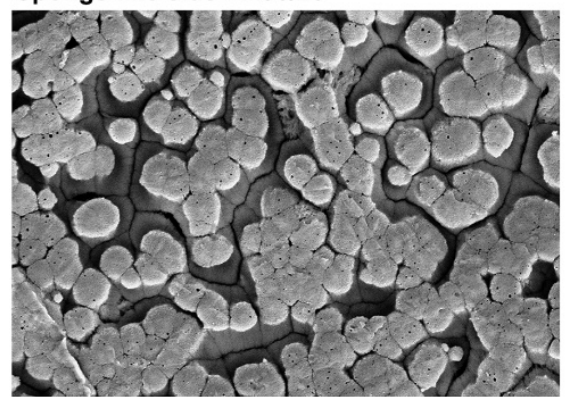

- $1 \mu \mathrm{m}$

Finger-like side - M90/20

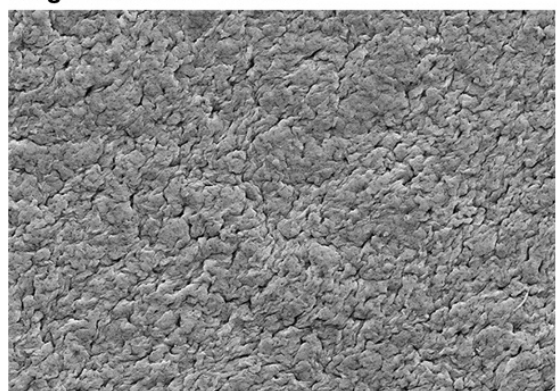

- $1 \mu \mathrm{m}$

Sponge-like side - M90/40

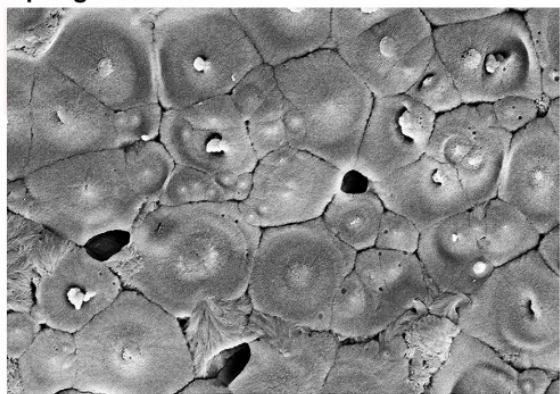

- $1 \mu \mathrm{m}$

Finger-like side - M90/40

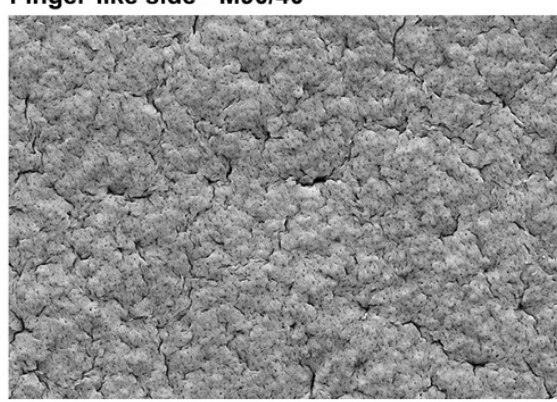

- $1 \mu \mathrm{m}$ (a)

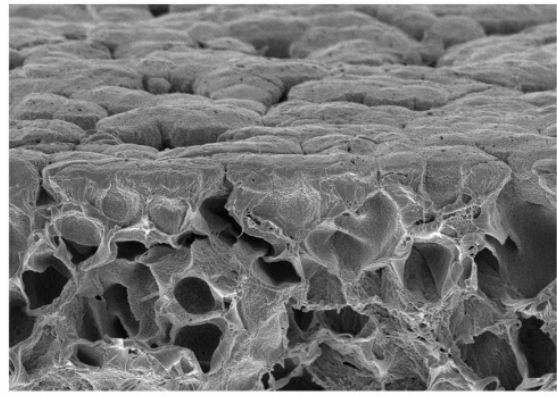

$-1 \mu \mathrm{m}$

(b)

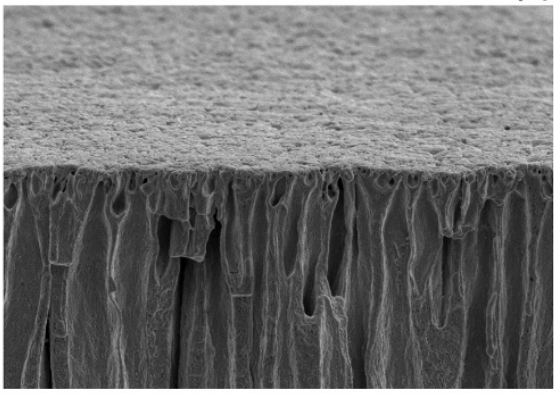

$-1 \mu \mathrm{m}$

(c)

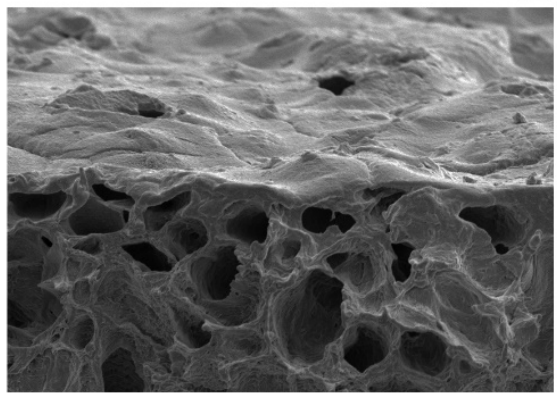

$-1 \mu \mathrm{m}$

(d)

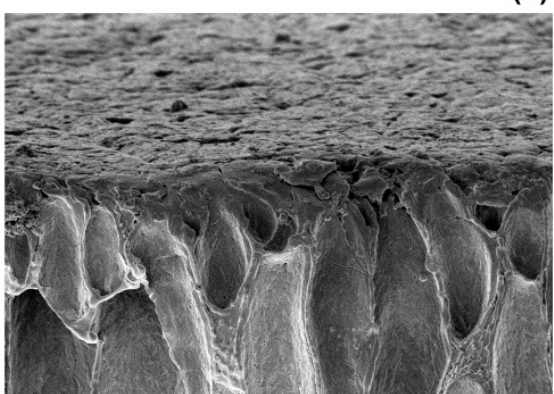

$-1 \mu \mathrm{m}$

Figure 8. SEM images of the surface (top and tilted view) of the membrane side with sponge-like morphology for (a) M90/20 and (c) M90/40, and with finger-like structures for (b) M90/20 and (d) M90/40. 
(a)

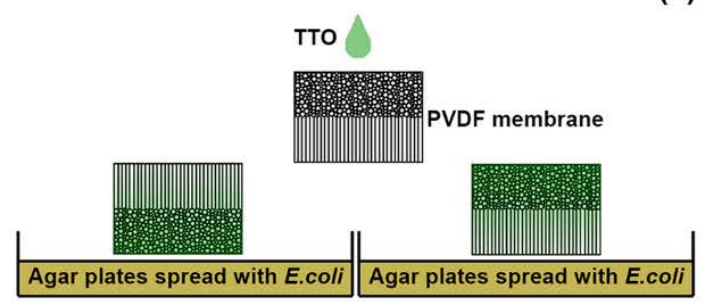

(b)
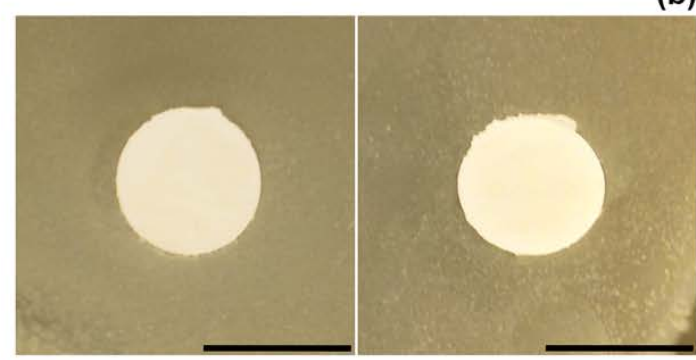

(c)
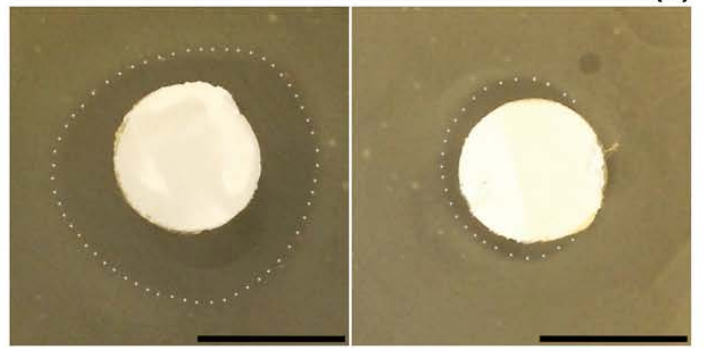

(d)

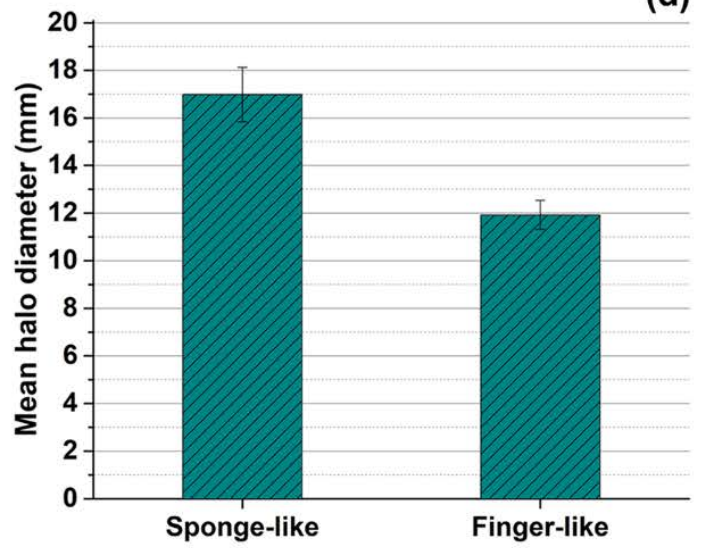

Figure 9. (a) Scheme of the procedure used to load the membranes with tea tree essential oil and to perform antibacterial tests. 8 samples were in contact with the Agar plate from the sponge-like side (left), and 8 samples from the finger-like side (right). Photographs of the in vitro antibacterial tests performed with (b) unloaded M90/40 membranes and (c) TTO-loaded M90/40 membranes. The white dotted line is a guide to the eye. Panels on the left-hand side are for sponge-like morphology; panels on the right-hand side are for finger-like morphology. 
Scale bar $=1 \mathrm{~cm}$. (d) Diameter of the inhibition halo for the sponge-like and the finger-like side of the membranes; $p<0.00001$. 
Table of Contents

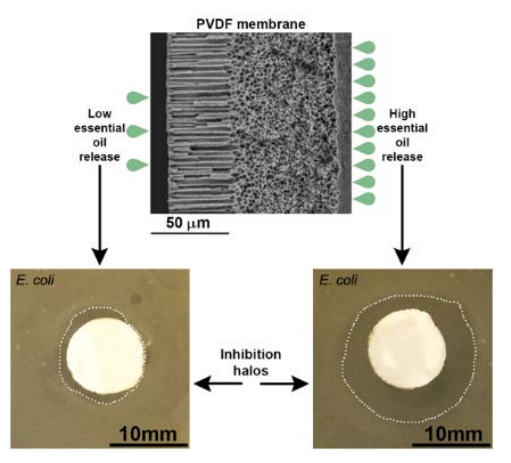

